\title{
Microbial load of dried moringa under rotary dryer in different storage and packaging conditions
}

\author{
I.P. Sudagar* ${ }^{1}$ and P. Aruna ${ }^{2}$ \\ ${ }^{1}$ Department of Food and Agric. Process Engg., and ${ }^{2}$ Department of Horticulture, TNAU, Coimbatore, \\ Tamil Nadu, India. \\ *Email: ipstnau@gmail.com
}

\begin{abstract}
Drumstick (Moringa oleifera Lam) belongs to the family Moringaceae. The shelf life of fresh moringa pods ranged between 3-5 days. This leads to heavy post harvest losses during peak season. Moringa pods were cut into chewable size of $2.5 \mathrm{~cm}$ length and used in rotary dryer and filled to 65 and 80 per cent of dryer volume. Dried samples were packaged using polypropylene and multilayer packaging materials under vacuum and as normal air packaging condition and were stored at ambient (Normal Temperature Pressure (NTP) and at cold storage condition for three months. Moringa pods of $2.5 \mathrm{~cm}$ length dried at $50^{\circ} \mathrm{C}$, filled to 65 per cent dryer volume in a rotary dryer, packaged in multi layer film, sealed under vacuum and stored at cold storage condition recorded minimum microbial load in multilayer packaging material.Among two storage conditions adopted, cold storage recorded minimum increase in microbial load value as compared to NTP storage.
\end{abstract}

Key word: Moringa pod, Rotary dryer, Microbial load, Packaging material, Storage.

Paper cited: Sudagar, I.P. and Aruna, P. (2018). Microbial load of dried moringa under rotary dryer in different storage and packaging conditions. South Asian Journal of Food Technology and Environment, 4(1): 628-630.

\section{Introduction}

Moringa (pod) is a very popular vegetable in South Indian cuisine and valued for its distinct flavour and its nutritional values and significant quantities of vitamin $\mathrm{C}$, calcium, iron, etc., and a good balance of all the essential amino acids. Drying reduces moisture content thereby it reduces microbial load of the produce to a level at which deterioration does not occur for a definite period of storage. The concept of microbial load is important in determining product quality and safety in a particular environment.

\section{Materials and methods}

Fresh moringa pods (Annual Moringa
type cv PKM-1) handpicked from
HC\&RI,TNAU, Periyakulam, Tamil Nadu were used for the study. Fresh moringa pods were washed in running tap water and pretreatment was given by dipping moringa pods in boiling water $\left(96^{\circ} \mathrm{C}\right)$ with magnesium oxide $(0.1 \%)$ for 15 seconds. As the moringa pod is too long to use as such, it was cut into of $2.5 \mathrm{~cm}$ in length (ready to cook size) and then used to conduct experiment. Drying reduces moisture content thereby it reduces water activity of the produce to a level at which deterioration does not occur for a definite period of storage. Chewable size moringa pods weighing 2778 and 3420 gram filled to 65 and 80 per cent of dryer volume at a moisture content $757.65 \pm 5.00$ per cent $(\mathrm{db})$ were dried in the rotary dryer at temperatures 40 and $50^{\circ} \mathrm{C}$ using hot air flow rate of $180 \mathrm{~m}^{3} / \mathrm{h}$ at $20 \mathrm{rpm}$ of drying chamber. The schematic diagram of the rotary dryer is shown in Fig. 1. After drying, moringa pods were packaged in Multilayer (ML) pouch (120 microns) and Polypropylene (PP) pouch (100 microns) following the vacuum packaging and normal air packaging methods and samples were stored in cold storage, $\left(7 \pm 1^{\circ} \mathrm{C}\right.$ and $80 \pm 5$ per cent relative humidity), at room condition (temperature $28 \pm 2^{\circ} \mathrm{C}$ and relative humidity $60 \pm 5$ per cent) storage conditions for three 
months. Microbial load was assessed by standard plate count method (Fortuny et al. 2004) for the enumeration of total bacteria, fungi and coli forms in the sample and were recorded at atmospheric temperature $(28 \pm$ $2^{\circ} \mathrm{C}$ ) and was done in triplicate. The data collected on various quality parameters during the study were statistically analyzed using software IRRISTAT 3/93 version for four factorial complete randomized design and reported.

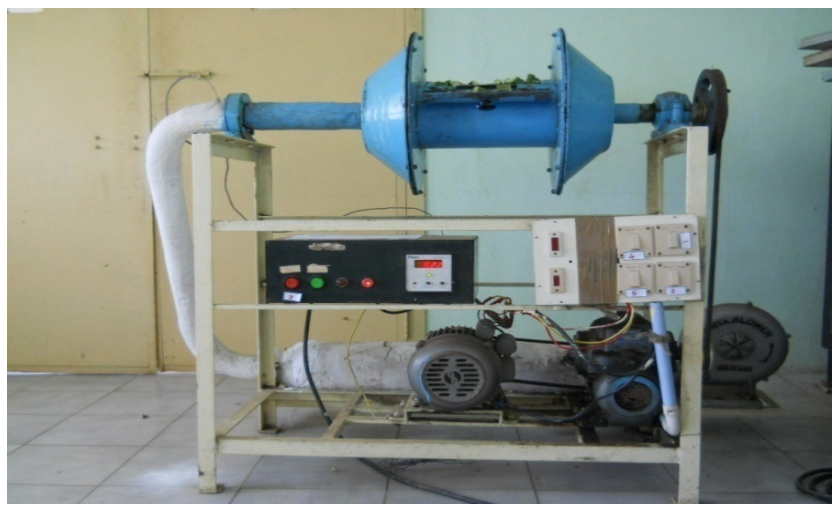

Fig.1: Rotary dryer

\section{Results and Discussion}

Moringa pods of $2.5 \mathrm{~cm}$ length filled to 65 per cent dryer volume dried at $50^{\circ} \mathrm{C}$ in a rotary dryer $(2.778 \mathrm{~kg})$ till it reached an equilibrium moisture content. Dried samples were packaged both in polypropylene and multilayer films under vacuum packaging and as normal air packaging. Packaged samples were stored both at NTP and cold storage condition for 90 days. Samples were drawn at monthly intervals to determine microbial load present in the stored samples. From figure 2, it is seen that the dried moringa pods packaged in multilayer film recorded a microbial load of $5 \times 10^{3} \mathrm{cfu} \mathrm{g}^{-1}$ of sample (dry matter) on the day of start of storage. From figure, it is also seen that irrespective of packaging materials used, samples packaged in normal air packaging recorded increased microbial population with increase in storage period. Dried moringa pods samples packaged under vacuum condition recorded a decreased microbial population in multilayer film packaging material with increase in storage period. Dried moringa pods samples packaged under vacuum condition recorded a decreased microbial population in multilayer packaging material with increase in storage period. This may be due to non availability of $\mathrm{O}_{2}$ under vacuum condition for the growth of aerobic micro organism and low water activity value $(0.603 \pm 0.01)$ and low moisture content value $(4.65 \pm 0.5$ per cent (dry basis)) prevailed in the sample acted as hurdles for growth of micro organism. Among two packaging materials used, multilayer film recorded the least microbial load. Among two packaging methods adopted, vacuum packaging recorded the lowest value. Among two storage conditions studied, cold storage recorded a minimum value as compared to NTP condition.

From Fig. 2, it is further seen that the moringa pods dried as above packaged under vacuum condition in multilayer film and stored at cold storage recorded minimum microbial load of $1 \times 10^{3} \mathrm{cfu} \mathrm{g}^{-1}$ of dried matter and sample stored at NTP in polypropylene material under normal air packaging recorded maximum microbial population of $8 \times 10^{3} \mathrm{cfu} \mathrm{g}^{-1}$ of dry matter after 90 days. From the analysis, it is seen that fresh moringa pods recorded a 
microbial load value of $18 \times 10^{4} \mathrm{cfu} \mathrm{g}^{-1}$ of dry matter of sample. Microbial load data recorded during storage of moringa pods and discussed above were statistically analyzed.

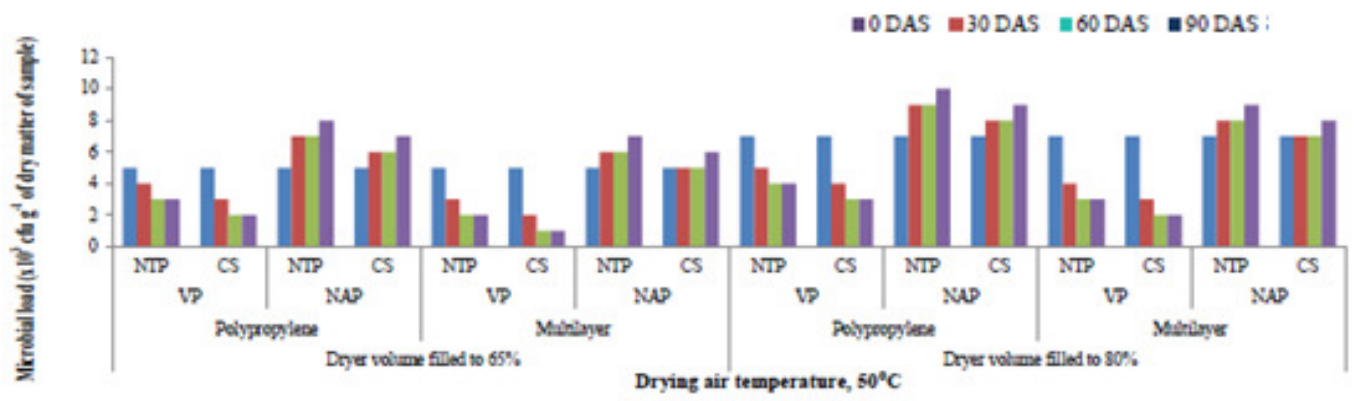

Fig.2. Effects of drying temperatures, drying chamber filled volumes, packaging materials, methods of packaging, storage conditions and days of storage on microbial load $\left(\mathrm{x}^{13} \mathrm{cfu}^{-1}\right.$ of dry matter) of $2.5 \mathrm{~cm}$ length moringa pods dried in a rotary dryer

\section{Conclusion}

Fortuny et al., (2004) reported that high barrier packaging materials were more responsible for both lower $\mathrm{O}_{2}$ and higher $\mathrm{CO}_{2}$ concentrations in the packaged head space throughout the storage. In the present study, multilayer packaging material used also has high barrier property, maintained low $\mathrm{O}_{2}$ concentration in the pouch and hence, recorded less microbial load. Moringa pods of $2.5 \mathrm{~cm}$ length filled to 65 per cent dryer volume, dried at $50^{\circ} \mathrm{C}$ in a rotary dryer, packaged in multilayer film as vacuum packaging and stored at cold storage recorded a minimum microbial load of $1.0 \times 10^{3} \mathrm{cfu}$ per $\mathrm{g}$ of dry matter after 90 days of storage. All other treatments recorded higher microbial load values. Hence, these experiment is considered as the best treatments under microbial load conditions. This treatment is highly suitable for export purpose.

\section{References}

1. Fortuny, R.C.L., Elez-Martinez, P. and Martin-Belloso, O. (2004). Microbiological and biochemical stability of fresh-cut apples preserved by modified atmosphere packaging. Journal of Innovative Food Science and Emerging Technologies, 5:215224.

\begin{tabular}{ll}
\hline Received & : March, 2018 \\
Revised & : April, 2018 \\
Published & : June, 2018
\end{tabular}

